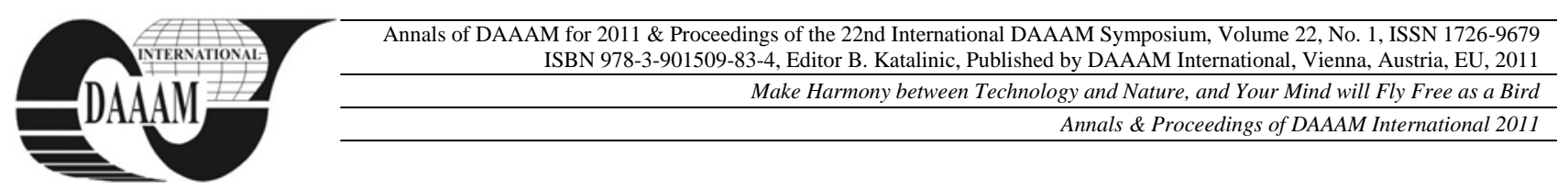

\title{
A METHOD OF WORKPLACE DESIGN FOR SEWING OPERATIONS
}

\author{
DRAGCEVIC, Z[vonko]; KIRIN, S[njezana] \& SARAVANJA, B[osiljka]
}

\begin{abstract}
The process of garment sewing belongs to piece manufacturing processes and is performed on production lines with a closed type of installed workplaces. The operations involved are performed in a sitting posture and working cycles of performing them are short (20-60s), with highly repetitive moves, which often results in occupational diseases due to extremely high psycho-physical loads. This is why it is necessary to design the working system (man-machineenvironment) for each workplace in accordance with static and dynamic anthropometric characteristics of each individual worker. The paper gives an overview of the basic procedure in workplace designing in sewing operations.
\end{abstract}

Key words: workplace design, sewing operations, sitting ergonomy, workload

\section{INTRODUCTION}

By the criterion of working process organisation, manufacturing systems in sewing belong to the closed type of workplace, with routine performance, where the operator performs the operations of approximately similar characteristics. To organise this type of work successfully, it is necessary to design the workplaces in a proper manner, selecting optimal methods of work for each technological operation, which offers the benefit of reducing the psychophysical load on the worker, the incidence of injuries and professional diseases, while, from the production point of view, it results in increased productivity and efficiency of work.

The process of sewing is an integral part of garment manufacturing. The work is performed in a sitting posture and the operator uses his trunk and arms in sewing to handle the workplaces and his feet to regulate sewing machine stitching speed. This kind of work asks for a repetitive and coordinated usage of the body, arms and legs, as well as a high ability to concentrate sight. A conditionally forced body and head postures often occur, physiologically improper sitting, isometric loads to the legs and considerable load to hands and fingers. Working body posture plays an important role in the operations of sewing (Dillard \& Schwager, 1997).

Improperly positioned working surface at the workplace, not matched to his/her bodily height, results in permanent static loads to the spine, arms and associated muscles. Such a workplace often leads to Cumulative Trauma Disorders (CTD), as well as pains and injuries in the discs, lumbar and cervical parts of the spine (scoliosis and kyphosis). (Vezina et al, 1992).

\section{WORKPLACE DESIGN}

When designing workplaces in sewing processes, it is necessary to create a dimensional balance of the man-machineenvironment manufacturing system, together with a physiologically appropriate sitting posture, such that would ensure quick and precise motor movements in positioning the workplace and machine actuation, high level of movement coordination, proper posture of the groin, back and cervical parts of the spinal column, as well as a proper position of the head.

Bodily measures and their mutual relationship differ from one person to the other making it difficult sometimes to adapt the working area to each individual operator. This is why the data on static and dynamic anthropometry are used to determine spatial conditions at particular workplaces. Proper matching with anthropometric relations ensures dimensional match between man and machine, which is reflected in beneficial angles of the kinematic chains: foot-lower leg; torso-head; torso-upper arm; upper arm-forearm-hand.

Proper arrangement of working zones ensures dynamic and rhythmic work enables combined and simultaneous movements to be performed by hands, legs and body, which all considerably reduces workload on the operator of technological sewing machine operation in garment industry. (Kirin et al, 2004).

\section{THE PROCEDURE OF WORKPLACE DESIGNING}

The following parameters should be determined in designing a workplace: sitting height, working surface height and distance, zones of normal and maximum reach and necessary fields of vision.

A group of static anthropometric measures of the operator, related to the particular working process performed in the sitting posture, should be defined when designing a particular workplace: torso thickness (A), upper leg thickness (B), popliteal lower leg thickness (C), upper leg length (D), shoulder height when sitting $(\mathrm{E})$, arm length $(\mathrm{F})$, elbow height from the sitting surface $(\mathrm{G})$, forearm length $(\mathrm{H})$, eye height when sitting (I).

Workplaces in sewing processes are designed through the following phases, (Fig.1):

- Working chair height - defined by the popliteal lower leg length $(\mathrm{C})$, with the addition of the ease for footwear $(2 \mathrm{~cm})$ and pedal regulator thickness $(5 \mathrm{~cm})$. This defines the plane of sitting as well (POS).

- Back contour plane (POL) is determined from torso thickness (A) with the addition of 15 to $20 \mathrm{~cm}$, representing the distance of the torso from the working surface edge (OUP plane).

- Working surface height (VUP) is determined according to the thickness of the upper leg increased by 10 to $15 \mathrm{~cm}$. The space bounded by the planes POL, OUP and VUP represents the borders of free space in which the operator has the necessary degree of free movement.

- The zones of normal and maximum reach define the abilities of arm movements in the working surface plane (VUP). The zone of normal reach is defined by the movement from the elbow $(\mathrm{H})$, where cyclic movement are performed, while the zone of maximum reach, or the zone of outstretched arm (F), includes periodic movements. 
- Angle of sight construction is determined according to the central plane of sight (SLV), which is defined by eye height when sitting (I). This enables the transfer of the standard line of sight within the limits of comfortable eye rotation by $25^{\circ}$ and comfortable head flexure by $30^{\circ}$ in the sagittal plane.

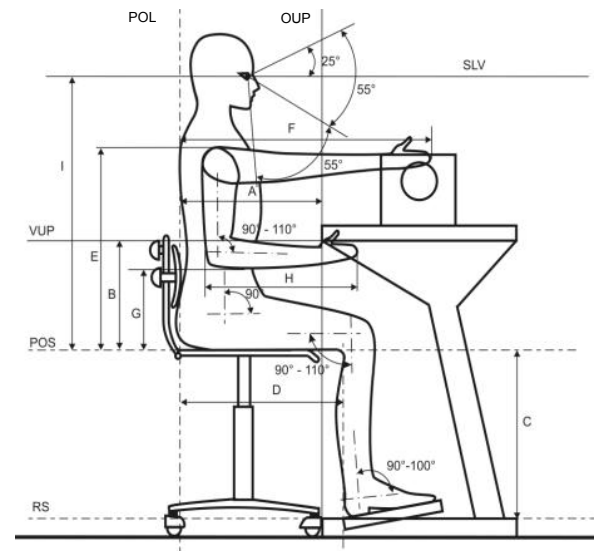

Fig. 1. The procedure of workplace design according to the data on operator's static anthropometric measures

The procedure of workplace design described here offers beneficial angles of the kinematic systems (foot/pedal regulator: $90-100^{\circ}$; lower leg - upper leg: $90-110^{\circ}$; upper leg torso: $60-90^{\circ}$ ). Proper angles of kinematic systems also ensure that the eyes are 30 to $40 \mathrm{~cm}$ from the central working zone of sewing, resulting in high visual acuity, necessary to control the sewing operation in a precise manner (Fig. 2). (Dragcevic et al, 2008).

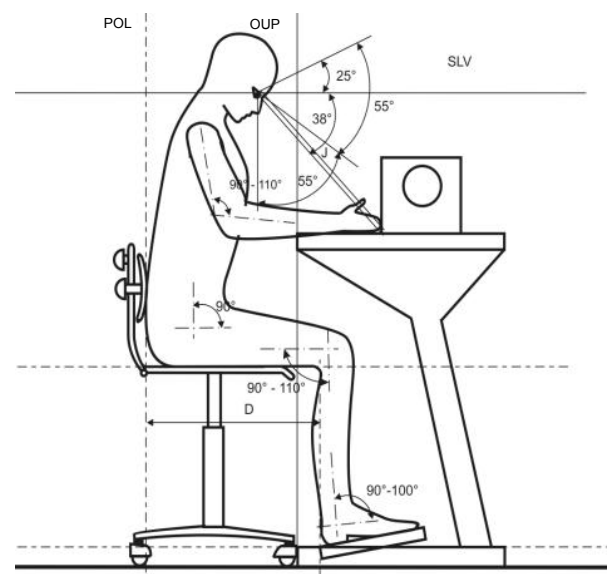

Fig. 2. Workplace designed for a normal sitting posture

The above posture is beneficial from the points of view of both physiological and anatomic requirements (Fig. 2)

Workplaces were designed using this method during some technical - technological projects funded by the Croatian garment industry (Varteks; Kotka; Pounje; and others). The model of workplaces designed and applied for actual sewing operations was verified through video recording analysis and using the OWAS (Ovako Working posture Analysis System) and PAQ (Position Analysis Questionnaire) methods.

The method developed is based on statistical anthropometric measurements of the operators. Having in mind specific characteristics of the work in sewing processes (short time of performing the operations), future investigations will be based upon necessary dynamic anthropometry and operator's body constitution: endomorphic, mesomorphic and ectomorphic type. (Rogale \& First Rogale, 2010).

The results indicated that the working postures and border angles of the kinematic systems (spine, upper and lower extremities, head) were within a normal and comfortable range, ensuring only minimal static and dynamic loadings (Fig. 3).

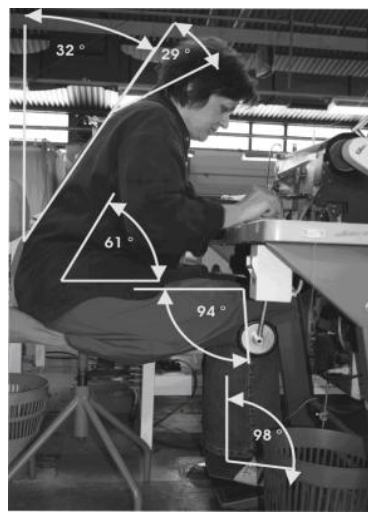

a)

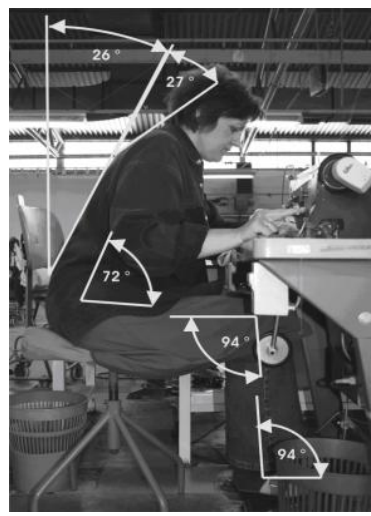

b)
Fig. 3. Border working postures in sewing operation, with associated angles of kinematic systems: workplace positioning (a), machine-hand sewing of a workplace (b)

\section{CONCLUSION}

The basic method of workplace design presented here offers considerably reduces psycho-physical loading of the operator, while enabling, from the manufacturing point of view, higher productivity or efficiency of the work performed. The investigations described indicated that the most operators working in sewing operations should be between 160 and 175 $\mathrm{cm}$ tall. With the operators outside of this range, it was impossible to achieve, when designing the workplace, working postures and angles of the kinematic system in the comfortable area. Basic notions of this method were used to develop a software package which enables a 3D visualisation of the workplace designed. The method could also be applied to workplace design in other manufacturing systems when the work is performed in a sitting posture (various assembling jobs, computer systems, office administration, etc.).

\section{ACKNOWLEDGEMENTS}

The paper presented is an integral part of the research within the confines of the scientific project entitled "Intelligent clothing and environment"; project code 117-1171879-1894, financed by the Ministry of Science, Education and Sports of the Republic of Croatia.

\section{REFERENCES}

Dillard, B. G.; Schwager, T.F. (1997). Ergonomic Equipment Investments Benefits to Apparel Manufacturers, International Journal of Clothing Science and Technology, Vol. 9, No. 4, 285-300, ISSN 0955-6222

Dragcevic, Z.; Kirin, S. \& Polajnar, A. (2008). Investigation of Workplace Design for the Process of Sewing, Proceedings of the 4th ITC\&DC, October 5th to 8th, Dubrovnik, Croatia, ISBN 978-953-7105-26-6, Dragcevic, Z, (Ed.), pp. 569-575

Kirin, S.; Dragcevic, Z. \& Polajnar, A. (2004). Workload and Fatigue in the Technological Sewing Process, Tekstil, Vol. 53, No. 5, 226-243, ISSN 04925882

Rogale, D., \& First Rogale, S., (2010). Human Body Constitution, In :Theoretical Aspects and Application of Croatian Anthropometric System (CAS), Ujevic, D., (Ed.), pp. 92-97, University of Zagreb, Faculty of Textile Technology, ISBN 978-953-7105-28-0, Zagreb, Croatia

Vezina, N. et al. (1992). Components of the Physical Workload of Sewing, Applied Ergonomics, Vol. 23, No. 4, 268-276, ISSN 0003-6870 